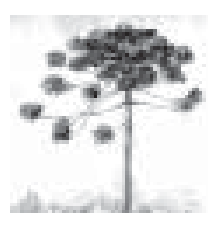

\title{
HOMEOPATIA NA TERAPIA DE ANIMAIS DE LABORATÓRIO NATURALMENTE INFECTADOS POR COCCÍDEOS
}

\author{
H omeopathy in the therapy of laboratory animals naturally infected by coccidea
}

\section{Aleksandro Schafer da Silva ${ }^{1}$, Claudia Dal Molin Soares ${ }^{1}$, Gabriela Pesamosca Coradini ${ }^{1}$, Camila Belmonte Oliveira1, Régis Adriel Zanette', Angélika Sharom², Silvia Gonzalez Monteiro ${ }^{3}$}

\footnotetext{
${ }^{1}$ Curso de Medicina V eterinária da Universidade Federal de Santa Maria (UFSM), Santa Maria, RS - Brasil.

2 Médica Veterinária Homeopata - ABRAH/ SP, Porto Alegre, RS - Brasil.

${ }^{3}$ Departamento de Microbiologia e Parasitologia da UFSM. Campus Universitário, Santa Maria, RS - Brasil, e-mail: sgmonteiro@uol.com.br
}

\begin{abstract}
Resumo
O trabalho visou avaliar a ação anticoccidiana de um complexo homeopático à base de A llium sativum, Carduus marianus e A rsenicum album em camundongos e ratos naturalmente infectados. Foram utilizados 20 camundongos (M us musculus) e 12 ratos (R attus norvergicus), infectados por coccídeos. D e cada espécie, os grupos controle e os grupos medicados com o complexo homeopático a base de A . sativum, C. marianus e A . album, na dose de 100 gotas para cada litro de água, foram analisados através de exame de fezes e pesagem a cada 10 dias durante 50 dias. 0 s roedores utilizados no experimento apresentavam infecção leve por coccídeos no início do experimento, a qual se manteve nos grupos controle até o final do estudo. O s camundongos eliminaram os coccídeos e os ratos apresentaram uma redução estatisticamente significativa no número de 0ocistos nas fezes após 50 dias. A solução homeopática utilizada foi eficaz no combate de coccídeos dos gêneros E imeria e C ystoisospora em camundongos infectados.
\end{abstract}

Palavras-chave: A llium sativum; C arduus marianus; A rsenicum album; E imeria; Cystoisospora.

\section{Abstract}

This study aimed to evaluate the anticoccidian action of a homeopathic complex including Allium sativum, Carduus marianus and Arsenicum album in mice and rats naturally infected. Twenty mice (Mus musculus) and 12 rats (Rattus norvergicus) infected by coccidea were evaluated. The control groups and the medicated groups of each species with the homeopathic complex at a dose of 100 drops/liter of water were evaluated during 50 days. Mice were weighed and had 
feces analyzed at 10-day intervals. Rodents used in this experiment showed mild infection by coccidea in the beginning of the experiment, whereas the control group maintained the infection until the end of the study. Mice eliminated the coccidea and rats showed a statistically significant decrease in the number of oocysts in feces after 50 days. The homeopathic complex was efficient in the control of coccidea of the genus Eimeria and Cystoisospora in infected mice.

Keywords A llium sativum; Carduus marianus; A rsenicum album; E imeria; Cystoisospora.

\section{INTRODUÇÃO}

Os coccídeos dos gêneros Eimeria e Cystoisopora são protozoários que pertencem ao filo A picomplexadasfamíliasEimeriidaee Sarcocystidae, de ampla distribuição geográfica (1, 2, 3). Esses parasitos podem causar doença clínica ou subclínica em diferentes espécies de animais domésticos e silvestres. Os coccídeos se multiplicam nas células intestinais causando máabsorção, desidratação, perda de sangue e aumento da susceptibilidade para outros agentes patogênicos $(1,4)$.

A homeopatiasefundamenta em princípios distintos da medicina convencional, aplicando 0 princípio de cura pela similitude, por meio de substâncias previamente experimentadas em indivíduos sadios, em doses infinitesimais. $\mathrm{Na}$ aplicação terapêutica desses pressupostos, valoriza a individualidade. A homeopatianão tem apenas efeitos curativos, ela é um excelente meio preventivo que possibilita melhor desempenho produtivo e reprodutivo dos animais. Profilaticamente já foi utilizada no controle de carrapato, berne, mosca-dochifre e das principais verminoses, não eliminando completamente os parasitos, mas levando a sua população para níveis que não causam danos econômicos $(5,6)$.

Plantas das espécies A llium sativum e $C$ arduus marianus e o mineral $A$ rseniaum album possuem constituintes que apresentam eficiência homeopática relacionada à estimulação de apetite, ação antimicrobial, anti-hipertensiva, antiateroesclerótica, antilipêmica, anticancerígena, hepatoprotetora, antioxidante, antiviral, antifúngica e antiparasitária $(7,8,9)$.

O objetivo deste trabalho foi avaliar a ação de um complexo homeopático à base de A . sativum, C. marianus e A a album no controle de coccídeos em camundongos e ratos naturalmente infectados.

\section{MATE RIAL E MÉTODOS}

O experimento foi realizado no biotério experimental do Laboratório de Parasitologia Veterinária da Universidade Federal de Santa Maria. No trabalho foram utilizados 20 camundongos (M us musculus) e 12 ratos (Rattus norvergicus), infectados naturalmente por coccídeos. Os animais foram divididos igualmente por espécie, sendo os grupos A e B formado por camundongos que apresentavam infecção mista por E imeria sp. e Cystoisospora sp. e os grupos C e D por ratos infectados por E imeria sp.. O s grupos A e $C$, grupos controle, não receberam tratamento e os grupos B e D foram tratados com o complexo homeopático à base de A . sativum, C. marianus e A . album na dose de 100 gotas para cada litro de água, diariamente, durante 50 dias. Os grupos foram formados por fêmeas com dois meses de idade, mantidas em temperatura e umidade controlada (25으 e $70 \%$ UA).

Durante o estudo foram realizados exames de fezes pelo método de centrífugo flutuação com sulfato de zinco (técnica de Faust), em intervalos de 10 dias (dia zero, 10, 20, 30, 40 e 50) (Tabela 1) . Nesses dias, os animais foram pesados e avaliados quanto à presença de sinais clínicos como, diarréia, pêlo seco e arrepiado e mortalidade, decorrentes da enfermidade em camundongos (10). A avaliação da carga parasitária foi baseada na classificação de Pinto et al. (11), onde consideram infecção leve 1-100 oocistos, moderada 101-300 oocistos e elevada mais de 301 oocistos/ lâmina.

A análise estatística dos dados foi feita através da análise de variância (ANOVA), seguida da aplicação do teste de TUKEY para comparação entre as médias, calculando-se 0 coeficiente de variação para verificar a precisão dos dados (12). 


\section{RESULTADOS}

Os roedores utilizados no experimento apresentaram infecção leve no início eno decorrer do tratamento, com exceção dos camundongos do grupo B que não apresentaram oocistos nas fezes após 50 dias (Tabelas 1 e 2). Nos exames físicos dos quatro grupos não se observaram sinais clínicos de parasitose (diarréia e pêlo seco), possivelmente devido ao grau leve de infecção em que se encontravam os roedores.
Após tratamento à base de solução homeopática observou-se a eliminação dos oocistos de coccídeos das fezes dos camundongos. Já os ratos tratados não eliminaram o parasito, no entanto, ocorreu uma redução significativa no número de oocistos do protozoário no final do experimento quando comparado ao grupo controle. Não se obteve diferença estatística entre 0 ganho de peso dos animais tratados e grupo controle de ambas as espécies animais no decorrer do experimento (Tabelas 1 e 2).

TABELA 1 - Número de oocistos e ganho de peso de camundongos naturalmente infectados com coccideos dos gêneros E imeria e Cystoisospora durante tratamento com complexo homeopático

\begin{tabular}{|c|c|c|c|c|c|}
\hline \multirow[t]{2}{*}{ Tratamento } & \multicolumn{5}{|c|}{ Número de oocistos de coccídeos por lâmina } \\
\hline & Dia 10 & Dia 20 & Dia 30 & Dia 40 & Dia 50 \\
\hline Grupo controle (A) & $20,2^{\mathrm{a}}$ & $31,0^{\mathrm{a}}$ & $16,8^{\mathrm{a}}$ & $10,2^{\mathrm{a}}$ & $11,8^{\mathrm{a}}$ \\
\hline \multirow[t]{3}{*}{ Grupo tratado (B) } & $25,0^{\mathrm{a}}$ & $18,2^{\mathrm{a}}$ & $4,6^{\mathrm{b}}$ & $1,8^{b}$ & $0,0^{b}$ \\
\hline & \multicolumn{5}{|c|}{ Ganho de peso em camundongos durante o experimento (gramas) } \\
\hline & Dia 10 & Dia 20 & Dia 30 & Dia 40 & Dia 50 \\
\hline Grupo controle (A) & $3,5^{\mathrm{a}}$ & $5,6^{\mathrm{a}}$ & $6,6^{\mathrm{a}}$ & $7,7^{\mathrm{a}}$ & $8,5^{\mathrm{a}}$ \\
\hline Grupo tratado (B) & $2,5^{\mathrm{a}}$ & $5,2^{\mathrm{a}}$ & $6,7^{\mathrm{a}}$ & $7,3^{\mathrm{a}}$ & $8,2^{\mathrm{a}}$ \\
\hline
\end{tabular}

Obs: Média seguida por letras iguais na mesma coluna não difere estatisticamente entre si a $5 \%$ de probabilidade do teste de TUKEY.

TABELA 2 - Número de oocistos e ganho de peso de ratos naturalmente infectados com coccideos por E imeria sp. durante tratamento com complexo homeopático

\begin{tabular}{llcccc}
\hline \multirow{2}{*}{ Tratamento } & \multicolumn{5}{c}{ Númeno de oocistos de coccídeos por lâmina } \\
& Dia 10 & Dia20 & Dia 30 & Dia 40 & Dia 50 \\
\hline \multirow{2}{*}{$\begin{array}{l}\text { Grupo controle(C) } \\
\text { Grupo tratado (D) }\end{array}$} & $52,6^{\mathrm{a}}$ & $41,0^{\mathrm{a}}$ & $46,8^{\mathrm{a}}$ & $30,2^{\mathrm{a}}$ & $21,8^{\mathrm{a}}$ \\
& $45,0^{\mathrm{a}}$ & $47,2^{\mathrm{a}}$ & $34,6^{\mathrm{b}}$ & $10,8^{\mathrm{b}}$ & $8,0^{\mathrm{b}}$ \\
\hline \multicolumn{7}{c}{ Ganho de peso em camundongos durante o experimento (gramas) } \\
& Dia 10 & Dia 20 & Dia 30 & Dia 40 & Dia 50 \\
Grupo controle(C) & $51,4^{\mathrm{a}}$ & $72,5^{\mathrm{a}}$ & $97,5^{\mathrm{a}}$ & $106,5^{\mathrm{a}}$ & $132,6^{\mathrm{a}}$ \\
Grupo tratado (D) & $45,0^{\mathrm{a}}$ & $77,6^{\mathrm{a}}$ & $88,6^{\mathrm{a}}$ & $102,4^{\mathrm{a}}$ & $128,2^{\mathrm{a}}$ \\
\hline
\end{tabular}

Obs: Média seguida por letras iguais na mesma coluna não difere estatisticamente entre si a $5 \%$ de probabilidade do teste de TUKEY. 


\section{DISCUSSÃO E CONCLUSÃO}

Neste estudo ocorreu a eliminação da infecção nos camundongos eumaredução do número de oocistos nas fezes dos ratos após tratamento com o pressuposto A . sativum, um dostrêsprincípios ativos. $\mathrm{Na}$ literatura não há registros de ação anticoccidiana paraconstituintes do alho, no entanto se sabe que allicina, um desses constituintes, in vitro, apresenta atividade antiparasitária contra E ntamoeba histolitica, A scaris lumbricoides, Giardia lambia, Trypanosoma brucei bruœi, T. b. rhodisiense, T. b. gambiense, $T$. evansi, $T$. congolense e $T$. equiperdum $(13,14,15,16)$.

Um dos ingredientes do composto homeopático, A . album foi utilizado no tratamento da malária na China (17). Pesquisadores avaliaram a eficácia da preparação homeopática com A . album em camundongos infectados por Plasmodium berghei everificaram controle de $70 \%$ da parasitemia dos roedores doentes (18). Além desse efeito malárico, não se tem comprovação científica desse componente na ação antiparasitária.

O C. marianus não apresenta ação antiparasitáriacomprovadaatéo momento, no entanto, apresentabonsresultados homeopáticosno tratamento de doenças hepáticas, como inflamações ou cirrose crônica, reduzindo os efeitos tóxicos para o organismo (19). Segundo os fabricantes, o complexo homeopático testado neste estudo mantém o funcionamento de glândulas, órgãos e hormônios (20).

O complexo homeopático administrado nos camundongos eliminou os coccídeos após 50 dias. O s ratos apresentaram uma redução significativa no número de oocistos nas fezes. $\mathrm{O}$ mineral $\mathrm{A}$. album e as plantas C. marianus e A . sativum juntos em uma solução homeopática apresentam-se eficazes no combate a coccídeos dos gêneros E imeria e Cystoisospora em camundongos infectados.

\section{REFERÊNCIAS}

1. Frenkel JK, D ubey JP. Rodents as vectors for feline coccidia Isospora felis and Isospora rivolta. J Infect D is. 1972 Jan;125(1):69-72.

2. Becker $\mathrm{CH}$, Heine J, Boch J. Experimentelle Cystoisospora canis und C. ohioensis infectionen bein hund. Tierarztl Umschau. 1981;36:336-41.
3. Shirley MW. Epizootiologia. A nais do Simpósio Internacional sobre coccidiose, FACTA Santos (Brasil): Nacional; 1994.

4. Mcdougald LR, Sibert BP. Residual activity of anticoccidial drugs in chickens after withdrawal of medicated feeds. Vet Parasitol. 1998 Jan 31;74(2-4):91-9.

5. Dias SAV. A Homeopatia e seu uso nos animais. Salvador: empresa baiana de desenvolvimento Agrícola S.A. EBDA Informa. 2002;(53):63.

6. Teixeira MZ. Panorama da pesquisa em homeopatia: iniciativas, dificuldades e propostas. Diagnóstico \& Tratamento. 2004;9(3):98-104.

7. Khanna KK, Chandra S. Control of tomato fruit rot caused by Fusarium roseum with homeopathic drugs. Indian Phytopathology. 1976;29:269-72.

8. Kemper KJ. G arlic (A llium sativum) [O nline] 2000. [cited 2007 jan 05]. Available from: http:/ / www.ccp.edu/ herbal/ default.htm

9. Gebhardt R. Antioxidative, antiproliferative and biochemical effects in HepG 2 cells of a homeopathic remedy and its constituent plant tinctures tested separately or in combination. Arzneimittelforschung. 2003;53(12):823-30.

10.Hoffmann RP. Diagnóstico de parasitismo veterinário. Porto Alegre: Sulina; 1987.

11.G onçalves L, Pinto RM, Vicente JJ, Noronha D, Gomes DC. Helminth parasites of conventionally maintained laboratory mice. Mem Inst O swaldo Cruz. 1998 JanFeb;93(1):121-6.

12. Silva FAZ, Azevedo CAV. Versão do programa computacional assistat para o sistema operacional Windows. Revista Brasileira de Produtos Agroindustriais. 2002;4(1):71-78.

13. Kalyesa R. Screening of indigenous plants for antihelminthic action against humam A scaris lumbricoides. Indian Journal of Physiology Pharmacology. 1975;19:47-9.

14.Blasi V. Amoebicidal effect of essencial oils in vitro. Journal de Toxicologie Clinique et Expérimentale. 1990;10(6):361-72. 
15.Lun ZR, Burri C, Menzinger M, Kaminsky R. Antiparasitic activity of diallyl trisulfide (dasuansu) on human and animal pathogenic protozoa (Trypanosoma sp., Entamoeba histolytica and $\mathrm{G}$ iardia lambria) in vitro. Annales de la Societé Belge de Médicine Tropicale. 1994;74(1):51-9.

16. Ankri S, Mirelman D. Antimicrobial properties of allicin from garlic. Microbes and Infectection/ Institut Pasteur. 1999;1(2):125-9.

17. Mendiola-Quezada, R. A rsenicum album. In: Adalpe-Barrera F. Farmacodinâmica Homeopática. UNAM (México); 1987. p. 216.

18. Lira-Salazar G, Marines-Montiel E, TorresMonzo J, Hernandez-Hernandez F, SalasBenito JS. Effects of homeopathic medications E upatorium perfoliatum and A rsenicum album on parasitemia of Plasmodium berghei infected mice. Homeopathy. 2006;95:223-8.

19. Kustrak D. A dry fruit extract of milk thistle (Silybum marianum (L.) Gaertn.) - A liver therapeutic. Farmaceutski Glasnik. 2000;56 (6):183-7.

20.Sharom A. Clínica de aves. [O nline] 2007. [acesso 2007 jan 05]. D isponível em: http:/ / www.clinicadeaves.com.br/ index.swf

Recebido: 03/ 02/ 2007

Received: 02/ 03/ 2007

Aceito: 10/ 03/ 2007

A ccepted: 03/ 10/ 2007 